\title{
Actinomyces graevenitzii pulmonary abscess mimicking tuberculosis in a healthy young man
}

\author{
Smaranda Gliga $M D^{1,2}$, Mathilde Devaux $M D^{2}$, Marine Gosset Woimant $M D^{2}$, Dominique Mompoint $\mathrm{MD}^{3}$, \\ Christian Perronne MD PhD², Benjamin Davido MD MS²
}

S Gliga, M Devaux, M Gosset Woimant, D Mompoint, C Perronne, B Davido. Actinomyces graevenitzii pulmonary abscess mimicking tuberculosis in a healthy young man. Can Respir J 2014;21(6): e75-e77.

Pulmonary actinomycosis is a rare disease that is often misdiagnosed as tuberculosis or lung cancer. Actinomyces graevenitzii is a relatively new recognized Actinomyces species isolated from various clinical samples. The authors report a case of pulmonary actinomycosis caused by A graevenitzii. A computed tomography examination revealed an excavated consolidation in the middle right lobe of a previously healthy young man who presented with a long history of moderate cough. Cultures of the bronchoalveolar lavage fluid confirmed the diagnosis of pulmonary abscess caused by A gravenitzii. At the three-month follow-up consultation and, after six weeks of highdose amoxicillin, the pulmonary lesion had completely disappeared.

Key Words: Actinomyces graevenitzii; Amoxicillin; Lung abscess; Pulmonary actinomycosis

Learning objectives:

- To recognize Actinomyces graevenitzii as a potential pathogen in pulmonary opacities in healthy patients.

- To understand the various steps used to identify and diagnose lung abscesses caused by A graevenitzii.

CanMEDS competency: Medical Expert

Pretest:

- What is the role of A graevenitzii in the pathogenesis of pulmonary actinomycosis?

- What are the different methods of laboratory diagnosis in pulmonary actinomycosis caused by A graevenitzii ?

\section{CASE PRESENTATION}

A 35-year-old man of Italian origin, born and living in France presented to hospital with a one-week history of profuse night sweats and productive cough with dark brown sputum. He had a one-year history of moderate cough and had recently travelled to Sicily, Italy. There was no previous contact with a contagious tuberculosis (TB) case.

Because of worsening symptoms, two days before admission, he consulted his general practitioner, who prescribed treatment with amoxicillin $1 \mathrm{~g}$ twice daily and a pulmonary $\mathrm{x}$-ray. The chest radiograph revealed an excavated middle lobe consolidation. Because of high clinical and radiological suspicion for pulmonary TB, he was referred to the infectious diseases department.

The patient was in good health before this episode. He underwent several minor surgical interventions during his childhood including appendectomy, tonsillectomy and inguinal hernia. There was no history of alcoholism, smoking, drug use, dental disease or facial trauma.

\section{Un abcès pulmonaire à Actinomyces graevenitzii imitant la tuberculose chez un jeune homme en santé}

Lactinomycose pulmonaire est une maladie rare souvent diagnostiquée à tort comme une tuberculose ou un cancer du poumon. L'Actinomyces graevenitzii est une espèce d'Actinomyces dépistée assez récemment dans divers échantillons cliniques. Les auteurs présentent un cas d'actinomycose pulmonaire causé par l'A graevenitzii. Une tomodensitométrie a révélé la condensation excavé du lobe moyen droit chez un jeune homme auparavant en santé qui avait une toux modérée depuis très longtemps. Les cultures du liquide de lavage bronchoalvéolaire ont confirmé le diagnostic d'abcès pulmonaire causé par l'A gravenitzii. Au moment de la consultation de suivi au bout de trois mois et après six semaines d'amoxicilline à forte dose, la lésion pulmonaire avait complètement disparu.

${ }^{1}$ National Institute of Infectious Diseases "Matei Bals", ADULTI III Department, Bucharest, Romania; ${ }^{2}$ Infectious Diseases Department;

${ }^{3}$ Radiology Department, Raymond Poincaré Teaching Hospital, Garches, France

Correspondence: Dr Smaranda Gliga, 6 Lunca Bradului str, sector 3, Bucharest, Romania. Telephone 40-72-802-9273,

e-mail smaranda.gliga@gmail.com 

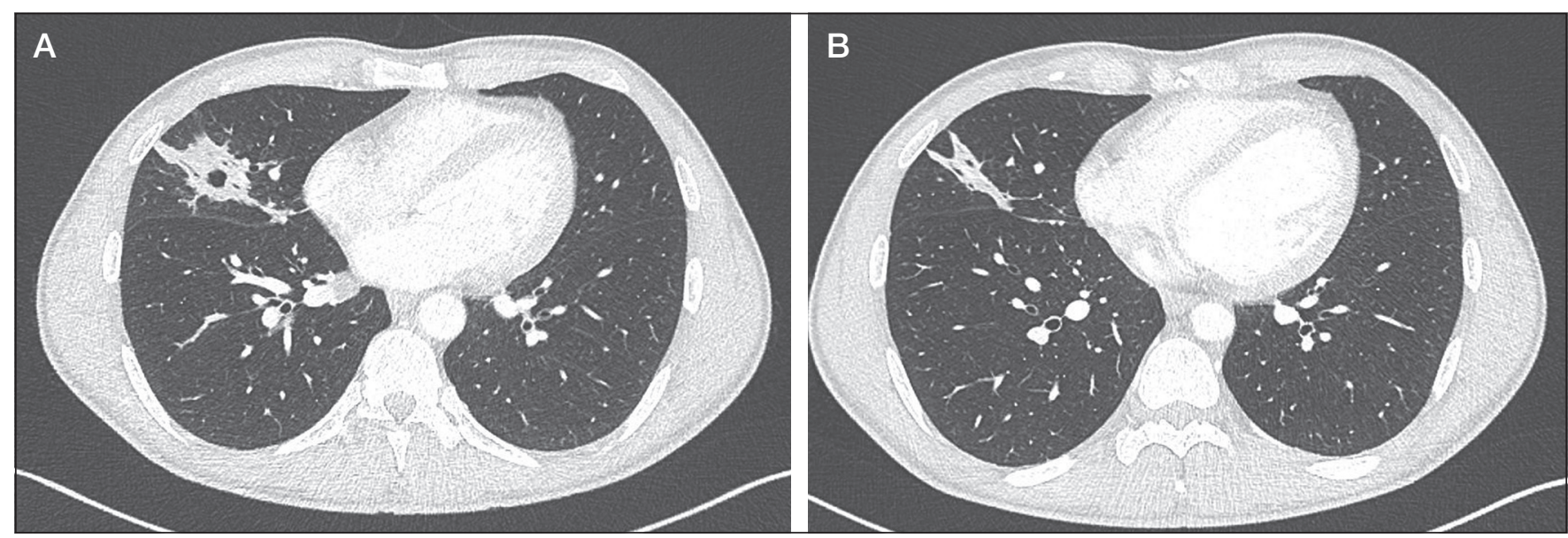

Figure 1) Chest computed tomography scans. A A nodule with cavitation was observed in the right middle lobe on admission. B The cavity had completely regressed, with persistence of a small consolidation three weeks after initiation of treatment

(Figure 1B). Clinically, the patient was asymptomatic. Six weeks after the cessation of antibiotic therapy, a pulmonary $\mathrm{x}$-ray showed complete healing, with total disappearance of the initial lesion. His C-reactive protein control level was negative. Complementary investigations did not reveal any primary immunodeficiency such as complement or immunoglobulin deficiency syndrome.

\section{DISCUSSION}

Actinomyces species are a Gram-positive, facultatively anaerobic bacteria belonging to the class Actinobacteria. Phylogenetic studies performed using $16 \mathrm{~S}$ ribosomal RNA sequencing have shown that there are $>30$ species in the genus Actinomyces, six of which are usually considered pathogenic in humans: Actinomyces israeli, Actinomyces gerencseriae, Actinomyces naeslundii, Actinomyces odontolyticus, Actinomyces viscosus and Actinomyces meyeri (1).

A graevenitzii was first described in 1997 by Ramos et al (2). Similar to other Actinomyces, A graevenitzii is a component of the oropharyngeal flora and was isolated from the surfaces of failed dental implants. However, little is known about the clinical features and pathogenesis of this bacterium. Only a small number of cases have been published describing pulmonary infections due to A graevenitzii (3-5). Other usual sources of A graevenitzii isolates are from pateints with osteomyelitis of the jaw, intra-abdominal lesion(s), and mouth and neck abscesses. To our knowledge, the present case is the first of pulmonary actinomycosis caused by $\mathrm{A}$ graevenitzii presenting as a single lung abscess, in the right apex, mimicking TB.

Pulmonary actinomycosis is a well-known cause of chronic pulmonary infection (1). The usual presentation is a slowly progressive pneumonia with fever, weight loss, cough, sputum and chest pain. Because clinical and radiological signs mimic malignancy and TB, it is often misdiagnosed and proper treatment is delayed. If the disease progresses to adjacent structures, life-threatening complications, such as massive hemoptysis or bronchoesophageal fistula, may occur. Important risk factors for thoracic actinomycosis include alcoholism, poor oral hygiene and underlying respiratory disease, all of which were absent in this patient.

Radiological aspects include a peripheral pulmonary nodule, mass or consolidation, all of which may or may not be cavitary or multifocal. In later stages, lung parenchyma may be destroyed and the infection may extend to the pleura or chest wall. Typical CT findings are reported as central areas of low attenuation within the consolidation in $62 \%$ to $75 \%$ of cases, and adjacent pleural thickening in $50 \%$ to $73 \%$ (6), which is consistent with the radiographic findings in the present case. Miliary presentations of the disease have also been reported.

Traditionally, diagnosis requires detection of sulfur granules by Gram-stain or histological examination. However, sulfur granules may occur in other infectious diseases such as nocardiosis and eumycetoma.
Special stains, such as Gomori methenamine-silver, may be needed to show that the sulfur granules are composed of branching bacteria and not fungi, cocci or bacilli. Because of inadequate anaerobic culture, previous antibiotic therapy or overgrowth of concomitant organisms, direct bacterial confirmation by culture is difficult and achieved in $<50 \%$ of cases (1). Culture of expectorated sputum or bronchoscopy aspirates are usually not successful, while fine-needle aspiration, transbronchial biopsy and CT or ultrasound-guided biopsies lead to accurate diagnoses $(1,6)$.

Because most Actinomycetales infections are polymicrobial in nature (7), a variety of other microorganisms are frequently found at infection sites in addition to Actinomyces species.

Regarding A graevenitzii, the pathogen was identified by quantitative culture of BALF $(4,8)$, but most cases required an amplified 16S ribosomal DNA restriction analysis $(2,3,5)$. In this case, diagnosis was obtained using quantitative culture of BALF. Nagaoka et al (4) argued that quantitative culturing of BALF is more reliable in differentiating respiratory tract pathogens from colonization related to pneumonia. They also showed that A graevenitzii had a faster growth rate (48 $\mathrm{h}$ to $96 \mathrm{~h}$ ) than other Actinomyces species that can be cultured anaerobically for up to three weeks. The faster growth rate of A graevenitzii may account for a different clinical presentation than traditional Actinomyces species, including aggressive disease in previously healthy patients.

Penicillin $G$ is considered to be the standard treatment for pulmonary actinomycosis (9). There are no guidelines regarding the duration of antibiotic treatment. In the past, high-dose intravenous penicillin was used for four to six weeks, followed by six to 12 months of oral penicillin A (amoxicillin). Recently, several investigators reported that shorter courses of treatment could be successful in pulmonary actinomycosis $(7,9)$. However, treatments shorter than three months may lead to local complications or recurrence.

Some patients have been successfully treated with oral antibiotics only (amoxicillin) (7). In the present case, the outcome was favourable despite the high dose of oral amoxicillin for only six weeks.

To our knowledge, only two in vitro studies have reported Actinomyces species drug susceptibility $(10,11)$. Recent reviews recommend that the first-line regimen consist of a beta-lactam with a betalactamase inhibitor $(10,12)$. Because resistance of the contaminating bacteria is often the cause of treatment failure, a beta-lactamase inhibitor offers the advantage of coverage against penicillin-resistant aerobic and anaerobic copathogens.

For patients who do not respond to antibiotics, surgery is an option. Other indications for surgical treatment are exclusion of a malignancy, uncontrolled hemoptysis, drainage of an abscess or pleural empyema, decortication and the radical excision of sinus tracts (13). 
The present case is uncommon because we report an atypical pulmonary abscess mimicking TB in a healthy patient with no comorbidities. More cases of pulmonary actinomycosis caused by $A$ graevenitzii and further information on this microorganism are needed to draw attention to this diagnosis when investigating pulmonary opacities. In cases in which actinomycosis is suspected, bacterial cultures of respiratory specimens should be performed. In cases in which cultures are negative, an amplified $16 \mathrm{~S}$ ribosomal DNA restriction analysis is necessary.

\section{Post-test}

- What is the role of A graevenitzii in the pathogenesis of pulmonary actinomycosis?

A graevenitzii is a component of the oropharyngeal flora. Usual sources of A graevenitzii isolates are failed dental implant surfaces, osteomyelitis of the jaw, intra-abdominal lesion, and mouth and neck abscesses. Only a small number of cases have been published describing pulmonary infections due to A graevenitzii (multiple pulmonary abscesses, organizing pneumonia) in patients with and without comorbidities. There were also two cases of disseminated infection in immunosuppressed patients, suggesting that A graevenitzii may also be an opportunistic agent.

- What are the different methods of laboratory diagnosis in pulmonary actinomycosis caused by A graevenitzii?

Diagnosis requires detection of sulfur granules by Gram-stain or histological examination. Direct bacterial confirmation by culture is difficult and is achieved in fewer than $50 \%$ of cases. A graevenitzii has a faster growth rate ( $48 \mathrm{~h}$ to $96 \mathrm{~h}$ ) than other Actinomyces species. Generally, culture of fine-needle aspiration, transbronchial biopsy and CT or ultrasound-guided biopsies are more accurate than sputum and bronchoscopy culture for the diagnosis of actinomycosis. However, A graevenitzii has been successfully identified using quantitative culture of BALF. When appropriate culture techniques are not available or there is a notion of previous antibiotic treatment, an amplified 16S ribosomal DNA restriction analysis can be very useful.

AUTHOR CONTRIBUTIONS: All authors participated in the preparation and review of the manuscript.
DISCLOSURES: The authors have no financial disclosures or conflicts of interest to declare.

\section{REFERENCES}

1. Mabeza GF, Macfarlane J. Pulmonary actinomycosis. Eur Respir J 2003;21:545-51.

2. Ramos CP, Foster G, Collins MD. Actinomyces graevenitzii sp. nov. isolated from human clinical specimens. Int J Syst Bateriol 1997; 47:46-53

3. Tietz A, Aldridge KE, Figueroa JE. Disseminated coinfection with Actinomyces graevenitzii and mycobacterium tuberculosis: Case report and review of the literature. J Clin Microbiol 2005;43:3017-22.

4. Nagaoka K, Izumikawa K, Yamamoto Y, Yanagihara K, Ohkusu K, Kohno S. Multiple lung abscesses caused by Actinomyces graevenitzii mimicking acute pulmonary coccidioidomycosis. J Clin Microbiol 2012;50:3125-8.

5. Fujita Y, Iikura M, Horio Y, Ohkusu K, Kobayashi N. Pulmonary Actinomyces graevenitzii infection presenting as organizing pneumonia diagnosed by PCR analysis. J Med Microbiol 2012;61:1156-8

6. Kim TS, Han J, Koh WJ, et al. Thoracic actinomycosis: CT features with histopathologic correlation. Am J Roentgenol 2006;186:225-31.

7. Choi J, Koh WJ, Kim TS, et al. Optimal duration of IV and oral antibiotics in the treatment of thoracic actinomycosis. Chest 2005;128:2211-7.

8. Cohen R, Bowie W, Enns R, Flint J, Fitzgerald M. Pulmonary actinomycosis complicating infliximab therapy for Crohn disease. BMC Case Rep 2009;bcr11.2008.1262

9. Brook I. Actinomycosis: Diagnosis and management. South Med J 2008;101:1019-23.

10. Prather JR, Eastridge CE, Hughes FA Jr, McCaughan JJ Jr. Actinomycosis of the thorax. Diagnosis and treatment. Ann Thoracic Surg 1970;9:307-12.

11. Smith AJ, Hall V, Thakker B, Gemmell CG. Antimicrobial susceptibility testing of Actinomyces species with 12 antimicrobial agents. J Antimicrob Chemother 2005;56:407-9.

12. Kolditz M, Bickhardt J, Matthiessen W, Holotiuk O, Hoffken G, Koschel D. Medical management of pulmonary actinomycosis: Data from 49 consecutive cases. J Antimicrob Chemother 2009;63:839-41.

13. Boudaya MS, Smadhi H, Marghli A, et al. Surgery in thoracic actinomycosis. Asian Cardiovasc Thorac Ann 2012;20:314-9. 


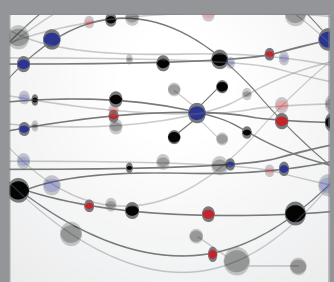

The Scientific World Journal
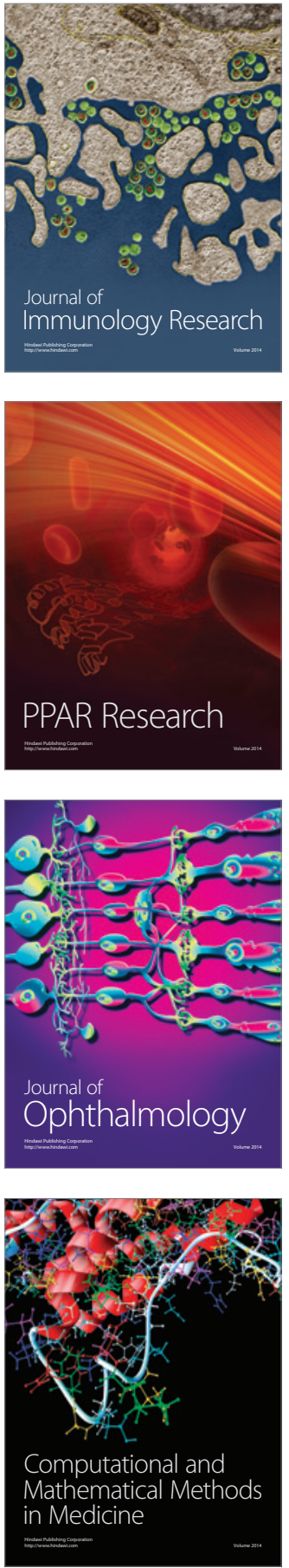

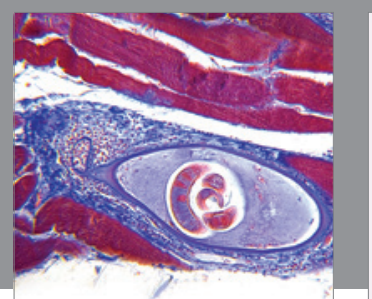

Gastroenterology Research and Practice

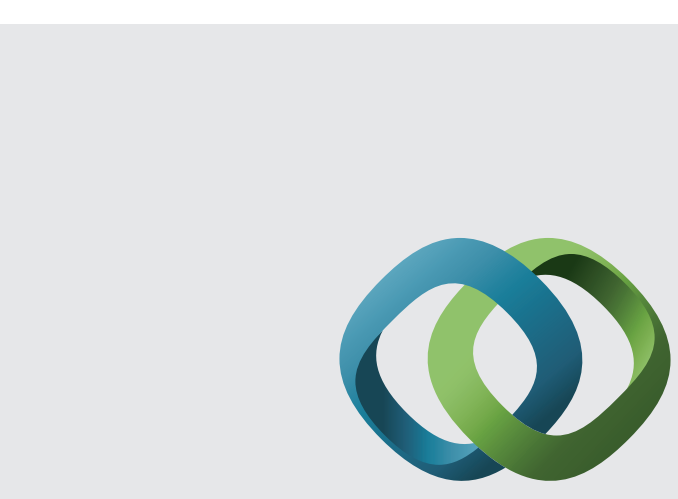

\section{Hindawi}

Submit your manuscripts at

http://www.hindawi.com
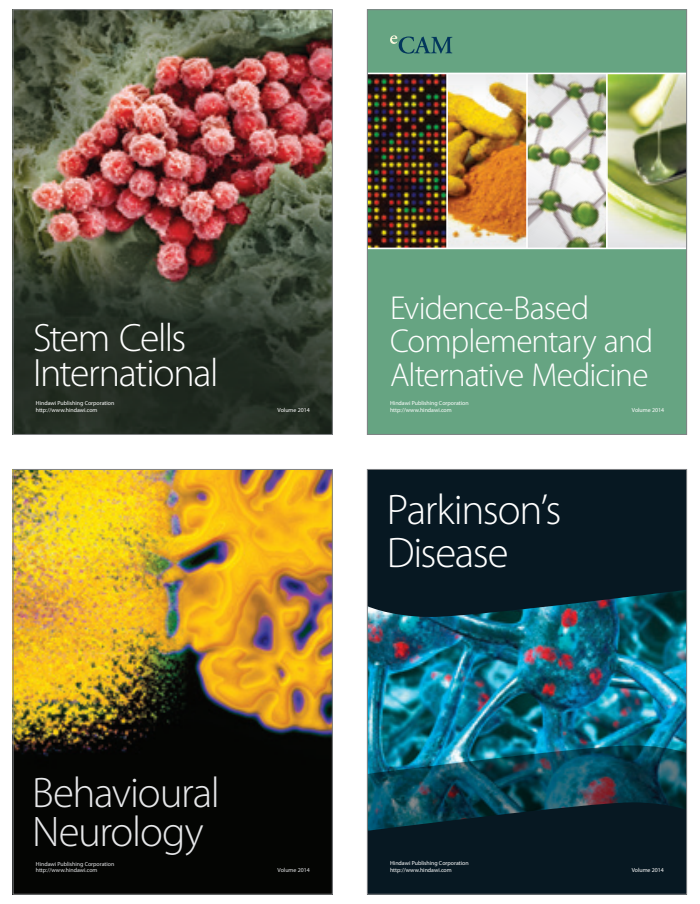
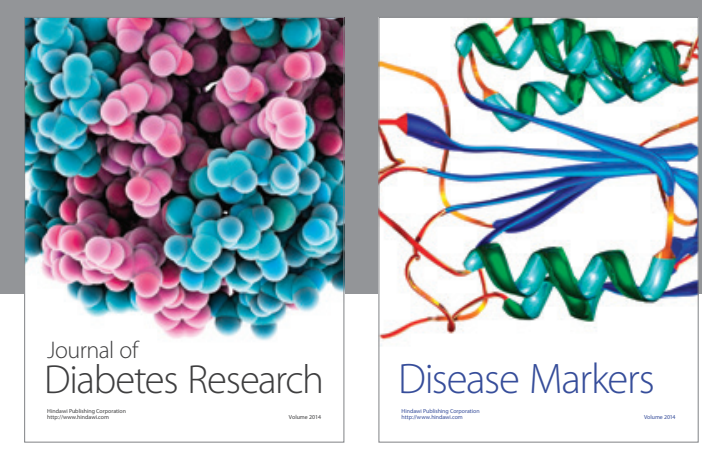

Disease Markers
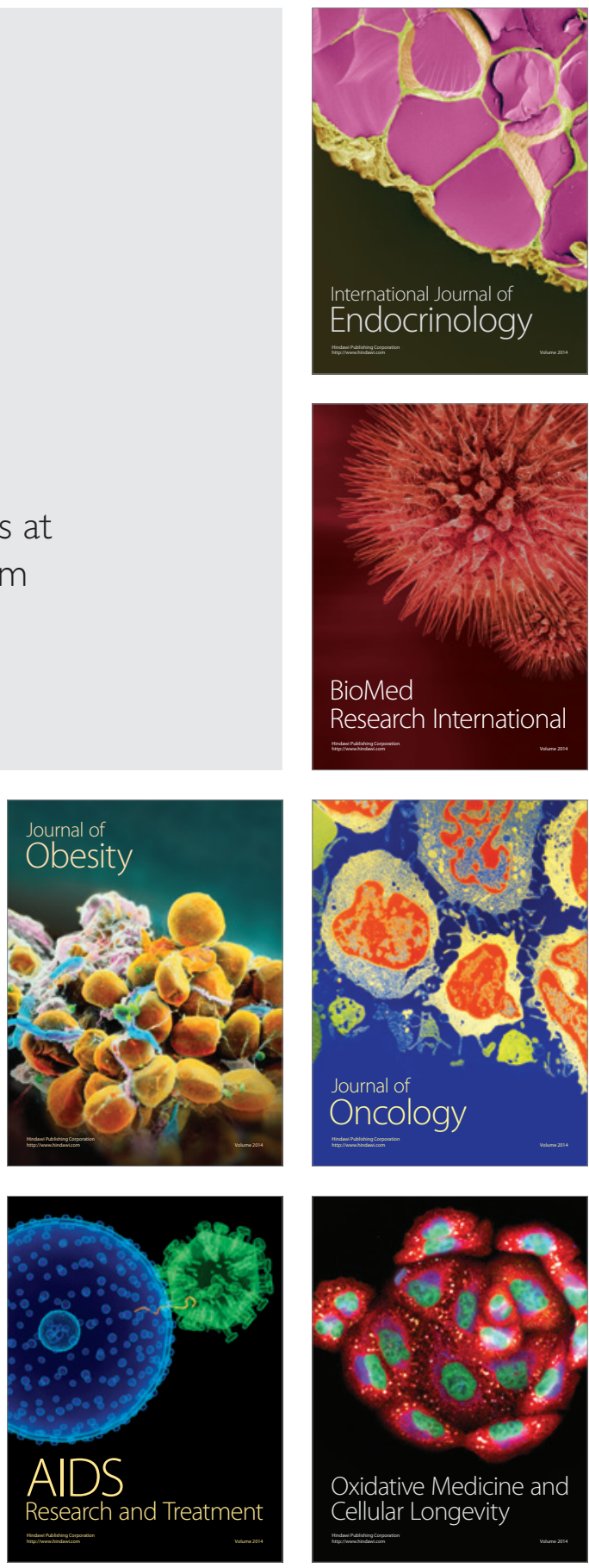